\title{
Thoughts on Diagnosis and Improvement of Nursing Specialty in Higher Vocational Education
}

\begin{abstract}
Qiu Zhi-chao
Shanghai Urban Construction Vocational College, Shanghai

286889341@qq.com

ABSTRACT

At the time of carrying out the work of professional diagnosis and improvement in the whole country, the nursing specialty of our school refers to the professional construction plan, and considers the following nine aspects: professional orientation, personnel training program formulation, school-enterprise integration, social service ability, characteristic specialty construction effect, teaching team construction, practical teaching conditions, social evaluation, education and teaching information platform construction, the establishment of normal operation of professional diagnosis reform mechanism, through the construction of network teaching platform to analyze the data to form a continuous improvement of professional diagnosis reform effect.
\end{abstract}

Keywords: nursing specialty in higher vocational education; diagnosis and improvement; thought

\section{高职护理专业的诊断与改进的思考}

\author{
邱智超
}

上海城建职业学院

286889341@qq.com

\section{摘要}

在全国推行专业诊断与改进工作的时机，我校护理专业参考专业建设规划，考虑从以下九方面入手， 即专业定位、人才培养方案的制定、校企融合度、社会服务能力、特色专业建设成效、教学团队的建 设、实践教学条件、社会评价、教育教学信息化平台建设, 建立常态运行的专业诊改机制, 通过建设 网络教学平台对数据进行分析, 形成持续改进的专业诊改效果。

关键词: 高职护理专业; 诊断与改进; 思考

\section{1. 前言}

2015 年 6 月, 教育部办公厅印发了《关于建立职业 院校教学工作诊断与改进制度的通知》提出以行业企业 用人标准为依据, 设计诊断项目, 以院校自愿为原则, 通过反馈诊断报告和改进建议等方式, 反映专业机构和 社会组织对职业院校专业教学质量的认可程度, 倒逼专
业改革与建设 [1]。诊改工作是在原有运行基础上增 加自我诊断和改进机制, 以利于及时发现问题。它是在 学校、专业、课程、教师、学生等五大层面开展常态化 的 “自我诊改” [2]。专业作为职业院校的办学基础, 是职业教育开展教学工作的基本单元。专业建设的水平 既反映了职业院校人才培养工作的水平, 也是学校办学 水平、教学质量和办学效益的重要标志 [3]。目前全 国准备铺开诊改工作，趁此时机找出我校护理专业在办 
学中存在的问题和不足, 扎实做好专业诊改工作, 做好 专业规划, 加强专业建设, 为后续的课程、师资、学生 等主体的诊改工作提供指导和借鉴 [4]。

\section{2. 专业建设的内部质量保证体系诊断项目}

专业建设是高校中最基本的工作，更是人才培养工 作的基础, 高等院校只有发挥自身特色、找准定位、恰 当切入、科学布局、合理规划专业建设, 才能发挥好专 业建设对人才培养的作用, 确保人才培养质量的提升。 2015 年 12 月教育部职成司印发《高等职业院校内部质 量保证体系诊断与改进指导方案（试行）»中，对于专 业质量保证包含 3 个诊断要素, 9 个诊断点。以及相对 应的影响因素参考。具体如下表 1 所示。

表 1 高职院校内部质量保证体系诊断项目参考表 ${ }^{[5]}$

\begin{tabular}{|c|c|c|c|}
\hline $\begin{array}{l}\text { 诊 } \\
\text { 断 } \\
\text { 项 } \\
\text { 目 }\end{array}$ & $\begin{array}{l}\text { 诊 } \\
\text { 断 } \\
\text { 要 } \\
\text { 素 }\end{array}$ & 诊断点 & 影响因素参考提示 \\
\hline \multirow{5}{*}{$\begin{array}{l}\text { 专 } \\
\text { 业 } \\
\text { 质 } \\
\text { 量 } \\
\text { 保 } \\
\text { 证 }\end{array}$} & \multirow{3}{*}{$\begin{array}{l}\text { 专 } \\
\text { 业 } \\
\text { 建 } \\
\text { 设 } \\
\text { 规 } \\
\text { 划 }\end{array}$} & $\begin{array}{l}\text { 规划制 } \\
\text { 定与实 } \\
\text { 施 }\end{array}$ & $\begin{array}{l}\text { 专业建设规划是否符合学 } \\
\text { 校发展实际, 是否可行; } \\
\text { 规划实施情况如何, 专业 } \\
\text { 结构是否不断优化。 }\end{array}$ \\
\hline & & $\begin{array}{l}\text { 目标与 } \\
\text { 标准 }\end{array}$ & $\begin{array}{l}\text { 有无明确的专业建设目标 } \\
\text { 和标准; 专业人才培养方 } \\
\text { 案是否规范、科学、先进 } \\
\text { 并不断优化。 }\end{array}$ \\
\hline & & $\begin{array}{l}\text { 条件保 } \\
\text { 障 }\end{array}$ & $\begin{array}{l}\text { 新增专业设置程序是否规 } \\
\text { 范; 专业建设条件 (经费、 } \\
\text { 师资、实验实训条件) 是 } \\
\text { 否有明确的保障措施。 }\end{array}$ \\
\hline & \multirow{2}{*}{$\begin{array}{l}\text { 专 } \\
\text { 业 } \\
\text { 诊 } \\
\text { 改 }\end{array}$} & $\begin{array}{l}\text { 诊改制 } \\
\text { 度与运 } \\
\text { 行 }\end{array}$ & $\begin{array}{l}\text { 学校内部是否建立常态化 } \\
\text { 的专业诊改机制; 是否能 } \\
\text { 够促成校内专业设置随产 } \\
\text { 业发展动态调整。 }\end{array}$ \\
\hline & & $\begin{array}{l}\text { 诊改效 } \\
\text { 果 }\end{array}$ & $\begin{array}{l}\text { 诊改成效如何, 人才培养 } \\
\text { 质量是否不断提高; 校企 } \\
\text { 融合程度、专业服务社会 } \\
\text { 能力是否不断提升; 品牌 }\end{array}$ \\
\hline
\end{tabular}

\begin{tabular}{|c|c|c|}
\hline & & $\begin{array}{l}\text { (特色/重点) 专业（群） } \\
\text { 建设成效、辐射影响力是 } \\
\text { 否不断增强。 }\end{array}$ \\
\hline & $\begin{array}{l}\text { 外部诊 } \\
\text { 断 (评 } \\
\text { 估 ) 结 } \\
\text { 论应用 }\end{array}$ & $\begin{array}{l}\text { 是否积极参加外部专业诊 } \\
\text { 断（或评估、认证）; 外 } \\
\text { 部诊断 (评估) 结论是否 } \\
\text { 得到有效应用, 对学校自 } \\
\text { 诊自改是否起到良好促进 } \\
\text { 作用。 }\end{array}$ \\
\hline \multirow{3}{*}{$\begin{array}{l}\text { 课 } \\
\text { 程 } \\
\text { 质 } \\
\text { 量 } \\
\text { 保 } \\
\text { 证 }\end{array}$} & $\begin{array}{l}\text { 课 程建 } \\
\text { 设规划 }\end{array}$ & $\begin{array}{l}\text { 课程建设规划是否科学合 } \\
\text { 理; 是否具有可行性与可 } \\
\text { 操作性。 }\end{array}$ \\
\hline & $\begin{array}{l}\text { 目标与 } \\
\text { 标准 }\end{array}$ & $\begin{array}{l}\text { 课程建设规划目标达成 } \\
\text { 度; 课程标准是否具备科 } \\
\text { 学性、先进性、规范性与 } \\
\text { 完备性。 }\end{array}$ \\
\hline & $\begin{array}{l}\text { 诊改制 } \\
\text { 度实施 } \\
\text { 与效果 }\end{array}$ & $\begin{array}{l}\text { 校内是否开展对课程建设 } \\
\text { 水平和教学质量的诊改, } \\
\text { 形成常态化的课程质量保 } \\
\text { 证机制; 是否对提高课程 } \\
\text { 建设水平和教学质量产生 } \\
\text { 明显的推进作用。 }\end{array}$ \\
\hline
\end{tabular}

\section{3. 专业建设规划是专业诊断的参考依据}

对于我校护理专业诊断与改进的指标体系的制定, 参考依据是我学院制定的护理专业的五年发展规划, 专 业建设规划包含三个诊断点, 即规划制定与实施、目标 与标准、条件保障。

\section{1. 专业建设规划是否符合学校发展实际, 是否可行, 这一点十分重要。}

因为科学的建设规划是在分析专业现状的基础上 制定的, 必须要符合发展的实际, 不能夸大其词。在实 施中要按照事先做好的规划, 逐步实施。根据社会需求 适当增设新的专业方向, 拓宽专业口径与专业的适应面, 促进各专业方向间互相支撑与共同增长。

\section{2. 在制定专业规划时要有明确的专业建设 目标和标准。}


建设目标是指专业要有明确的办学规模、办学条件、 办学水平, 具体来说是把专业建设成什么样子。对外指 它的社会声誉, 对内指在校内的地位。建设标准是将专 业建设细化分解成具体的建设任务, 形成可监测、可量 化、可描述的数据或指标, 是建设目标的具体化、数量 化、任务化。具体来说就是毕业生就业的核心岗位以及 相对应的岗位的知识、能力、素质要求。

\section{3. 专业建设条件包括经费、师资、实验实 训条件是否有明确的保障措施。}

专业建设是否有足够的经费投入, 这是保证专业建 设的最基本的条件, 只有经费足额到位, 才能进行专业 建设; 师资是诊改工作的主体, 是否有学科带头人、双 师素质教师、是否加强对师资队伍的建设, 注重教师的 个人成长, 是进行诊改工作的最重要的保障之一; 实习 实训基地是专业实践教学的基本保障, 实训室的面积、 数量、功能、设备等等这些基本的要素一定要满足专业 实践教学要求。以上这些基础保障措施是实现专业发展 的必要条件, 是专业建设的基础。

\section{4. 专业诊改的指标体系}

根据目前影响我校护理专业发展的因素, 依据专业 建设规划, 从以下九方面对专业建设工作进行全面的诊 断, 并提出诊改意见。具体的影响专业建设的九方面的 指标体系如下。

\section{1. 专业定位}

专业必须准确定位。在专业建设中要确保与经济发 展、社会需求有效对接, 解决好 “学校与社会” 的接口 问题。目前, 随着社会的发展人们的健康观念的转变, 社会对护理专业人才的需求呈现了多样化。尤其是专科 护理人才和老年护理专业人才大量缺乏, 因此我校护理 专业必须要根据市场需求, 在专业设置方面做出调整, 增加了新的专业方向。

\section{2. 人才培养方案的制定}

人才培养方案要科学。它是人才培养的指导性文件, 包含人才培养目标、人才培养规格、课程体系架构的设 计。培养目标是指培养什么样的人才, 根据人才培养目 标要求, 确立培养规格。课程体系是人才培养质量的重 要前提和保障, 是人才培养目标的重要载体, 因此课程
体系必须要科学, 注意学生各方面能力的培养, 注重人 的全面发展; 课程设置必须要合理, 注意各课程模块所 占的比重, 尤其要注意理论和实践的课程比例; 教学内 容要对接行业、职业标准, 注重对学生动手能力的培养。

\section{3. 校企融合度}

学校和企业要深入合作。高职教育的培养目标是培 养实用型专门人才, 也就是说必须要培养出行业、企业 用得上的人才。因此在教学过程中, 必须要参照行业、 职业的标准, 开展校企合作项目, 产教融合, 协同育人, 尤其是专业性强的护理专业, 必须要做到与临床的零距 离接轨。

\section{4. 社会服务能力}

学校要具有一定的社会服务能力。作为人才培养的 重要基地-大学, 必须要承担一定的社会服务, 首要任 务是培养的人才为当地产业经济发展提供支持。其次, 能承接各种职业技能培训, 能为行业、企业的科研项目 提供支撑，能够产生一定的社会效应。

\section{5. 特色专业建设成效}

特色是专业建设的根本所在。高校的专业都是根据 国家专业目录或有关国家政策引导下设置的，但是不同 学校的同名专业一般都具有不同的特色与背景。专业特 色不仅是一所学校办学特色的所在, 也是一所学校人才 培养质量的所在, 更是一所学校的生命所在。因此一定 要突出特色, 自己的优势, 使得我们培养出来的人才在 不同层面上适应经济建设和社会发展的需要。

\section{6. 教学团队的建设}

专业诊断与改进实施的主体是教师。这项工作是需 要全员参与、全程诊断、全方位改进的。因此需要建立 一个良好的团队。而目前我校的教学团队面临着严重的 问题, 一是人员缺乏, 目前我国职业教育院校分公办和 民办两种：民办中由于投资主体不同，性质也不同，结 果造成政策平面上的差异，如：工资、社保、户籍、子 女入学等都无法与公办高职高专院校相比, 人才保留机 制非常脆弱, 这种状况必将造成优秀人才的流失, 也很 难招聘到优秀的人才; 二是, 年龄结构、职称结构存在 严重不合理现象。高职称教师不足, 低职称教师偏多; 
年青教师偏多, 缺少中青年骨干教师。而这样的现状严 重影响了专业的建设和发展。在诊改工作准备全面推行 的时候, 这个问题凸显出来, 也是影响专业诊改工作顺 利进行的非常重要的因素。当然, 这也是教学团队、师 资队伍建设的好时机，因为领导们都已经看到了阻碍专 业建设和发展的关键因素; 三是高职护理专业人才培养, 需加强 “双师” 结构的专兼教师队伍建设, 这是提升学 生的职业能力和就业质量的保证。因此充分利用专业诊 改的契机，加强建设一支 “工学融合、专兼结合” 的 “双 师型”结构护理教学团队, 以培养符合现代服务需要、 具有新型服务理念、德才兼备的优秀高技能型护理人才。

\section{7. 实践教学条件}

护理专业是一个实践性很强的专业, 在课程计划中 理论课与实验实训课的比例大于 $1: 1$ 。为满足学生技能 训练的需要, 必须要加强对校内和校外实训基地的建设。 校内建设模拟真实职业环境、符合医院和我国护理行业 要求的护理实训中心，满足护理专业学生实训的需要; 校外与医院建立诚信的合作教育关系, 签定共建校外实 习基地协议书, 保障校外临床实习工作有序、顺利进行。

\section{8. 社会评价}

社会评价是对学校培养出的人才质量进行实践性 的确认。而这种评价方式能反映出学校所培养出的人才 质量, 这一点也是教育发达国家最重视而常采用的评价 手段 [6]。而社会对一个学校教育教学质量的认可, 必须要考察以下几个指标: 学生就业率、护士执业资格 证书通过率以及学校的招生情况。

\section{8. 1. 用人单位满意度, 学生就业率}

高职院校的毕业生就业率是反映学校办学水平、培 养质量和综合实力的重要指标, 同时它更标志着学校教 学建设、专业与教学质量、管理与服务等一系列工作的 水平 $[7]$ 。

\subsection{2. 考证通过率}

近几年, 随着护士执业资格证考试制度的改革, 学 生在毕业前就要参加全国护士执业资格证的考试。因此, 考证的通过率成了衡量人才培养质量的一个十分重要 的指标。

\subsection{3. 招生规模}

招生规模体现出专业的社会辐射能力, 近几年上海 普遍生源大幅减少, 外省生源竞争日趋激烈, 一些高职 院校的招生陷入困境。学生招生的录取率和报到率可以 反映出社会对这个专业的认可度。

\section{9. 教育教学信息化平台建设}

诊改工作主要基于对学校人才培养工作状态数据 的分析, 辅以灵活有效的实际调查研究。提升教育教学 管理信息化水平。强化人才培养工作状态数据在诊改工 作中的基础作用, 促进高职院校进一步加强人才培养工 作状态数据管理系统建设与应用, 完善预警功能, 提升 学校教学运行管理信息化水平 [8]。

诊改工作是在原有工作基础上的诊改, 它是对工作 过程中数据的实时采集, 通过对动态数据的分析从而找 出问题所在，对于诊改工作提供最重要的数据支持。因 此教育教学信息平台的建设是对于专业建设过程的信 采集, 它对于在专业建设过程中, 师资队伍的情况、课 程情况等能够体现专业建设内容的痕迹, 动态的体现出 来, 能够从中发现问题, 为诊改工作提供重要的支持与 服务, 也为持续改进提供重要的数据资源。

\section{5. 专业诊改的质量保证措施}

\section{1. 建立常态运行的专业诊改机制}

学校应该建设自我诊断的专业诊改制度, 要以企业 用人单位的需求、根据技术进步、服务产业升级来调整 人才培养方案, 每年开展专业调研, 做好第三方评估工 作, 即用人单位、家长、社会的满意度调查, 按照 “ 8 ” 字形螺旋递进的诊改要求, 对于专业诊改指标体系进行 自我诊断与改进，形成诊断报告。同时找出影响专业发 展存在的主要问题, 分析问题产生的原因, 形成有针对 性的诊改方案并落实 [9]。

\section{2. 形成持续改进的诊改效果}

专业诊改效果主要看人才培养质量是否不断提高; 校企融合程度、专业服务社会能力是否不断提升; 品牌 (特色/重点) 专业（群）建设成效以及辐射影响力是 否不断增强, 专业建设的效果是否为其他学校关注。通 过数据信息管理平台考核以上九个指标，对学校自诊自 改起到良好的促进作用。促进专业的发展。

专业诊改工作是一件学术性和行政性兼而有之的 工作，既不能简单采用行政化的方法，也不能采用纯学 
术化的方法, 而要由学校在充分掌握教育部相关文件精 神基础上结合校本实际加以落实 [10]。由此可见, 这 是一件 “自上而下” 的工作, 是由学校领导做好顶层设 计, 各专业在现有基础上找到自身存在的问题, 找到最 适合自身专业发展的路径和措施, 持续改进和完善, 促 进专业人才培养质量不断提高。

\section{REFERENCES}

[1] Ministry of education. Notice on establishing the diagnosis and improvement system of teaching work in Vocational Colleges [Z]. Jzct [2015] No. 2, 2015-06-23

[2] [2016]. Higher vocational education system improvement and development

[3] Wan de Nian. Design of evaluation of professional talent training in Vocational Colleges [J]. Journal of Xiangyang vocational and technical college, 2015 (4)

[4] Wande year. How to make professional diagnosis and improvement in Higher Vocational Colleges [J]. Vocational and technical education, 2017, 38 (17)

[5] Ministry of education. Guidance scheme for diagnosis and improvement of internal quality assurance system in Higher Vocational Colleges (Trial) [Z]. Jzcsh [2015] No. 168, 2015-12-30

[6] Xun Yusen. Reflections on the research of teaching quality evaluation in higher vocational education. Vocational Education Forum, 2003 (12)

[7] Tao Lingfeng. How to improve the employment level of Higher Vocational Graduates under the new situation (J). Journal of Wuhu Vocational and technical college, 2012 (2)

[8] Dai Yong. Thinking on several problems of medical reform in Higher Vocational Colleges ( J ). Mechanical vocational education, 2016 (7)

[9] Li Yucai. Design and diagnosis of "professional" quality control points in internal quality assurance system of Higher Vocational Colleges [J]. Science and technology economics guide, 2017 (24)

[10] Zhang Hongbin. Basic ideas on the objectives, standards and methods of professional diagnosis reform in Higher Vocational Colleges ( J ). Times education, August 2017 